Check for updates

Cite this: RSC Adv., 2019, 9, 37497

Received 15th October 2019

Accepted 8th November 2019

DOI: $10.1039 / c 9 r a 08410 j$

rsc.li/rsc-advances

\title{
Biophysical restriction of growth area using a monodispersed gold sphere nanobarrier prolongs the mitotic phase in HeLa cells $\uparrow$
}

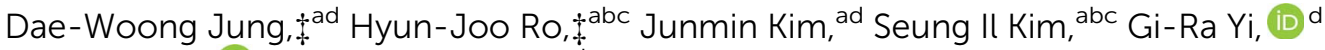 \\ Gaehang Lee (D) ${ }^{* a}$ and Sangmi Jun*abc
}

\begin{abstract}
Gold nanoparticles are widely exploited for biological and biotechnical applications owing to their stability, biocompatibility, and known effects on cellular behaviors. Many studies have focused on nanoparticles that are internalized into cells, but extracellular nanoparticles also can regulate cell behavior, a practice known as in-plane surface nanotopography. We demonstrated that nanobarriers composed of morphologically homogeneous gold nanospheres prolonged the mitotic (M) phase in the cervical cancer cell line HeLa without inducing apoptosis. The nanobarrier was formed by electrostatic deposition of nanospheres on a negatively charged, fibronectin-coated substrate. We tested the effects of differently sized nanospheres. Gold nanospheres $42 \mathrm{~nm}$ in diameter were found to be non-toxic, while $111 \mathrm{~nm}$ nanospheres induced the production of reactive oxygen species, resulting in apoptotic cell death and arrest of cytokinesis. When exposed to sufficient $83 \mathrm{~nm}$ gold nanospheres to fabricate a surface nanobarrier, the $\mathrm{M}$ phase was delayed but cells proceeded to cytokinesis and the G1 phase. Live-cell imaging showed that the $\mathrm{M}$ phase increased by $2.9 \mathrm{~h}, 2.4$ times longer than in control cells. Biophysical analyses indicated that this could be attributed to the specific size of the nanobarrier that physically limited the growth area around the cell.
\end{abstract}

\section{Introduction}

The use of gold nanoparticles (AuNPs) in biomedical and biotechnical applications ${ }^{1-3}$ has been a subject of increasing attention, given their unique biocompatibility, ${ }^{4}$ low cytotoxic effects, ${ }^{5}$ stability, easy functionalization as platforms for molecular conjugation, ${ }^{6}$ and efficiency as drug delivery agents. ${ }^{7}$ Several in vivo and in vitro studies have elucidated numerous AuNP parameters, including size, ${ }^{8}$ shape,${ }^{1}$ concentration, ${ }^{9}$ and surface chemistry, ${ }^{10}$ that affect cellular uptake and cytotoxicity. Their biological effects include regulation of cell proliferation by cell-cycle arrest and apoptosis induction mediated by nanotoxicity. ${ }^{11,12}$

Most nanoparticle-based studies focus primarily on cellular cues induced by their internalization, with considerably less

aKorea Basic Science Institute, Daejeon, 34133, Republic of Korea. E-mail: ghlee@kbsi. re.kr; smjun@kbsi.re.kr

${ }^{b}$ Convergent Research Center for Emerging Virus Infection, Korea Research Institute of Chemical Technology, Daejeon, 34114, Republic of Korea

'Bio-Analytical Science, University of Science \& Technology, Daejeon, 34113, Republic of Korea

${ }^{d}$ Department of Chemical Engineering, Sungkyunkwan University, Suwon, 16419, Republic of Korea

$\dagger$ Electronic supplementary information (ESI) available. See DOI: 10.1039/c9ra08410j

\$ Equal contribution. emphasis on extracellular cues. ${ }^{13,14}$ Intercellular AuNPs are used in biomedical applications including drug delivery ${ }^{15}$ and sensing of target molecules ${ }^{16}$ by actively interacting with cellular components. The consequences of these interactions then change the regulation of cell behavior. Nanomaterials surrounding cells constitute an artificial extracellular matrix, providing a combination of external chemical, physical, mechanical, and biological factors that can influence cell behavior. ${ }^{17}$ AuNPs are the most commonly used components for in-plane nanotopography; ${ }^{17-19}$ the characteristics of cell surface nanotopography result in multiple cellular responses including locomotion, ${ }^{20}$ spreading, ${ }^{21}$ differentiation, ${ }^{22}$ adhesion, ${ }^{23}$ and cell-cycle progression. ${ }^{24}$

The cell cycle is universally critical for the development, survival, and reproduction of all organisms. Specifically, the $\mathrm{M}$ phase involves dramatic changes in multiple cellular structures, leading to nuclear (mitosis) and cytoplasmic (cytokinesis) division. ${ }^{25}$ Therefore, M-phase control is the focus of intense interest in cancer $^{26}$ and longevity ${ }^{27}$ research. Conventionally, delays in the cell cycle caused by a chemical treatment could be interpreted as a response to the modulation of a cell-cycle regulator or delaying the assembly of the mitotic spindle, resulting in an incomplete cell cycle process, such as DNA replication or chromosome alignment. ${ }^{28,29}$ However, this also causes unintended damage, such as apoptosis, ${ }^{28}$ which interrupts the goal of the study. Advanced methods or new 
technological platforms are required to modulate cell-cycle progression without causing such damage.

Herein, we demonstrate a novel strategy to prolong the $\mathrm{M}$ phase in the cervical cancer cell line HeLa, without nuclear DNA damage. The procedure was realized using a nanobarrier with highly spherical and monodispersed gold nanospheres electrostatically attached to a fibronectin-coated substrate. Cells were imaged for $24 \mathrm{~h}$ to determine their biological responses to the external physical stimuli produced by in-plane nanotopography, as well as to nanoparticle internalization of spheres with 42, 83, and $111 \mathrm{~nm}$ diameters. The effects of the nanobarriers on cells were particle size dependent. External nanobarriers made with $83 \mathrm{~nm}$ spheres physically retarded cell movement, preventing cells from securing a sufficient growth area, inducing an increase in the mean duration of the $\mathrm{M}$ phase and delaying the cell cycle.

\section{Materials and methods}

\section{Materials}

Ethylene glycol (EG, anhydrous, 99.8\%), gold(III) chloride trihydrate $(49.0 \%$ metals basis), poly(dimethyldiallylammonium chloride) (polyDADMAC, molecular weight 400-500 kDa, 20 wt $\%$ in $\left.\mathrm{H}_{2} \mathrm{O}\right)$, phosphoric acid $\left(\mathrm{H}_{3} \mathrm{PO}_{4}, 85 \mathrm{wt} \%\right.$ in $\left.\mathrm{H}_{2} \mathrm{O}\right)$, polyL-lysine $\left(0.1 \%\right.$ in $\left.\mathrm{H}_{2} \mathrm{O}\right)$, and fibronectin (Bioreagent, $0.1 \%$ in $\mathrm{H}_{2} \mathrm{O}$ ) were purchased from Sigma-Aldrich (USA). Amine-polyethylene glycol-thiol $\left(\mathrm{NH}_{2}-\mathrm{PEG}-\mathrm{SH}, 10 \mathrm{k}\right)$ was prepared by Creative PEGworks (USA). HeLa cells (human adenocarcinoma cells originating from the cervix, \#CCL-2) were purchased from the American Type Culture Collection (USA).

\section{Preparation of N-AuNSs}

We modified the synthesis process outlined in a previous report to better control AuNS size..$^{30}$ PolyDADMAC (8.0, 9.1, and $\left.10.0 \mathrm{~g}\right)$, $\mathrm{H}_{3} \mathrm{PO}_{4}$ solution $(16 \mathrm{~mL}, 1 \mathrm{M})$, and EG $(400 \mathrm{~mL})$ were mixed in a $1 \mathrm{~L}$ glass bottle at room temperature. $\mathrm{HAuCl}_{4}$ solution $(0.4 \mathrm{~mL}$, $0.5 \mathrm{M}$ ) was added to the mixture. The bottle was incubated at $190{ }^{\circ} \mathrm{C}$ without stirring for $3 \mathrm{~h}$. To etch octahedral Au particles into nanospheres, $\mathrm{HAuCl}_{4}$ solution $(0.1 \mathrm{~mL}, 0.5 \mathrm{M})$ was added to the cooled suspension, followed by vigorous stirring at $25{ }^{\circ} \mathrm{C}$ for $24 \mathrm{~h}$. Centrifugation at $50000 \mathrm{~g}$ (Supra 30k, Hanil, Republic of Korea) for $2 \mathrm{~h}$ and repeated washing with ethanol yielded spherical AuNSs. For surface modifications on the AuNSs, $\mathrm{NH}_{2}-$ PEG-SH solution ( $3 \mathrm{~mL}, 1 \mathrm{mM}$ ) was added to $1 \mathrm{~mL}$ of $1.0 \times 10^{10}$ NSs per $\mathrm{mL}$ aqueous suspension. The mixture was stored at $30^{\circ} \mathrm{C}$ for 6 days. N-AuNSs were separated from the resultant suspension by centrifugation and purified by washing with water.

\section{Measurement of the number of $\mathrm{NH}_{2}$ groups on the N-AuNS surface}

The UV/visible absorbance of the amine-reactive fluorescein isothiocyanate (FITC) fluorescent dye was measured at concentrations of $100,50,10,5,1$, and $0.5 \mu \mathrm{M}$ in ethanol. Each maximum absorbance was fitted to a GaussAmp curve using Origin 8.0 software (Fig. S1A $\dagger$ ) (1) and plotted using eqn (1):

$$
y=y^{\mathrm{o}}+A \exp \left(-0.5 \times\left(\frac{x-x^{\mathrm{c}}}{W}\right)^{2}\right)
$$

where $x$ is the absorbance of the FITC solution, $y$ is the molar concentration of the FITC dye, $y^{\circ}$ is the offset on $y$ axis $(-4.9 \times$ $\left.10^{-7}\right), A$ is the amplitude of each curve $\left(1.3 \times 10^{-4}\right), x^{c}$ is the center position on the $x$-axis of each GaussAmp curve (1.7), and $W$ is the width of each curve $\left(5.3 \times 10^{-1}\right)$. Samples $(1 \mathrm{~mL})$ of 1.7 $\times 10^{9}, 4.2 \times 10^{10}$, and $4.2 \times 10^{10} \mathrm{NSs}$ per $\mathrm{mL}$ for 42,83 , and $111 \mathrm{~nm}$ wide $\mathrm{N}$-AuNSs, respectively, were mixed with $1 \mathrm{~mL}$ of $0.4 \mathrm{M}$ FITC solution and shaken at $500 \mathrm{rpm}$ at room temperature for $12 \mathrm{~h}$. To measure free FITC, the supernatant was collected by centrifugation at $2500 \mathrm{~g}$ for $20 \mathrm{~min}$. The maximum absorbance of free FITC in each supernatant is presented in Fig. S1B. $\dagger$ The concentration of FITC that reacted with the amine groups on the AuNSs could be calculated by substituting the difference in the absorbance of the dye before and after the reaction into eqn (1). As shown in Table $S 1, \dagger$ by identifying the number of labeled amines, the number of amine groups per AuNS could be calculated.

\section{Primary characterization of N-AuNSs by TEM}

Nanoparticles dispersed in water were placed on a copper 200mesh grid (Electron Microscopy Sciences, USA) and examined by ultra-corrected energy filtering transmission electron microscopy (UC-EF-TEM), ZEISS Libra with $200 \mathrm{kV}$ (ZEISS, Germany). The microscope was equipped with a high-tilted goniometer, a monochromator (CEOS, Germany), an image Cs-corrector (CEOS, Germany), and a side CCD camera (ORIUS SC200D, Gatan, USA).

\section{Cell culture}

HeLa cells were cultured in Dulbecco's modified Eagle's medium supplemented with $10 \%$ fetal bovine serum and $1 \% 100 \times$ antibiotic-antimycotic solution (Gibco-BRL, USA). Cells were seeded in 4-chamber glass-bottom dishes and 96-well cell culture plates (Matek Corporation, USA) pre-coated with human fibronectin solution or poly-L-lysine solution (Sigma-Aldrich, USA). Cells were incubated in a humidified incubator at $37{ }^{\circ} \mathrm{C}$ with $5 \% \mathrm{CO}_{2}$ and passaged at $80-90 \%$ confluence. For each experiment, cells cultured in medium without N-AuNSs were used as controls. The cells were seeded $24 \mathrm{~h}$ prior to AuNS exposure at a density of 5.0 $\times 10^{3}$ per well in the 96-well plates and $2.0 \times 10^{4}$ per chamber in the 4 -chamber dish, aiming to reach $70 \%$ confluence.

\section{Cell proliferation assay}

Cell proliferation was assessed using a cholecystokinin (CCK)-8 assay (Dojindo Molecular Technologies, USA), according to the manufacturer's instructions. Cells were seeded in transparent 96-well plates and exposed to the 42, 83, and $111 \mathrm{~nm} \mathrm{~N}$-AuNS dispersions at $4.2 \times 10^{7}, 2.1 \times 10^{9}, 4.2 \times 10^{9}$, and $8.4 \times 10^{9}$ NSs per mL for $24 \mathrm{~h}$. Next, CCK-8 $(10 \mu \mathrm{L})$ reagent was added to each well and incubated for $3 \mathrm{~h}$ at $37{ }^{\circ} \mathrm{C}$ with $5 \% \mathrm{CO}_{2}$. After incubation, absorbance at $450 \mathrm{~nm}$ was measured using a Synergy H1 Hybrid Multi-Mode Reader (BioTek, USA). 


\section{Flow cytometry for cell cycle analysis}

The distribution of cells in each phase of the cell cycle was studied using a propidium iodide flow cytometry kit (Abcam, USA). Approximately $3.0 \times 10^{5}$ cells per well were seeded in 96well plates and exposed to $83 \mathrm{~nm}$ and $111 \mathrm{~nm} \mathrm{~N}$-AuNSs at $4.2 \times$ $10^{7}$ and $2.1 \times 10^{9} \mathrm{NSs}$ per $\mathrm{mL}$ for $24 \mathrm{~h}$. Cells were harvested and centrifuged at $120 \mathrm{~g}$ for $3 \mathrm{~min}$. According to the manufacturer's instructions, the pellet was fixed in $66 \%$ ethanol and stored at $4{ }^{\circ} \mathrm{C}$ for $2 \mathrm{~h}$. The fixed cells were rehydrated in PBS, then stained with propidium iodide and RNase for $30 \mathrm{~min}$. The stained cells were then analyzed using a flow cytometer with the propidium iodide fluorescence intensity set to FL2 and $488 \mathrm{~nm}$ laser excitation with maxima for excitation $493 \mathrm{~nm}$ and emission $636 \mathrm{~nm}$. Total 5 trials of cell cycle analysis were conducted and their average value with standard deviation represented in Fig. 5.

\section{Cell morphology, live-cell imaging, and measurement of mitochondrial ROS}

HeLa cells in 96-well culture plates $(200 \mu \mathrm{L}$ of aqueous mixture of N-AuNSs and cell culture media) exposed to $4.2 \times 10^{7}$ and 2.1 $\times 10^{9} \mathrm{NSs}$ per $\mathrm{mL}$ of 42,83 , and $111 \mathrm{~nm} \mathrm{~N}$-AuNSs and the equivalent ratio of nanoparticles per cells were applied in a 4chamber dish $(800 \mu \mathrm{L}$ of aqueous mixture of N-AuNSs and cell culture media). Cells were imaged on an Olympus IX71 inverted microscope (40× magnification) equipped with a fully automated 96-well plate Chamlide stage-top incubator (Live Cell Instrument, Republic of Korea) for $24 \mathrm{~h}$. Cells were maintained at $37{ }^{\circ} \mathrm{C}$ in a humidified atmosphere of $5 \% \mathrm{CO}_{2}$ throughout the experiment. Time-lapse images were acquired as 20-25 zsections at $1 \mathrm{~h}$ intervals for each position. Stage displacement and image acquisition were controlled through MetaMorph (Universal Imaging, USA). For measurement of $\mathbf{M}$ phase duration, approximately 10 cells were picked per $1 \mathrm{~h}$ time-lapse image series, so the average value is represented in $1 \mathrm{~h}$ units. The videos were made from $1 \mathrm{~h}$ interval time-lapse images captured over a $22 \mathrm{~h}$ period.

Mitochondrial reactive oxygen species (ROS) were detected using the MitoSOX ${ }^{\mathrm{TM}}$ Red mitochondrial superoxide indicator (Life Technologies, USA). Cells were seeded in 96-well plates and exposed to $4.2 \times 10^{7}$ and $2.1 \times 10^{9} \mathrm{NSs}$ per mL of 83 and $111 \mathrm{~nm}$ $\mathrm{N}$-AuNSs for $24 \mathrm{~h}$. Cells treated with a common ROS inducer, tert-butyl hydroperoxide (TBHP), were used as a positive control (Fig. S2 $\dagger$ ). Cells were stained with NucBlue Live ReadyProbes Reagent (Invitrogen, Eugene, OR) and MitoSOX Red, according to the manufacturer's instructions, to detect nuclei and mitochondrial ROS, respectively. An Olympus IX71 inverted microscope $(40 \times$ magnification) was used to image fluorescence with excitation and emission wavelengths of 405 and $460 \mathrm{~nm}$ for NucBlue, and 510 and $580 \mathrm{~nm}$ for MitoSOX Red.

\section{Cellular uptake of N-AuNSs visualized by cryo-EM and TEM}

Cells were ready to be examined by cryo-electron microscopy (cryo-EM) and TEM after $24 \mathrm{~h}$ of incubation with N-AuNSs. Plunge-freezing of HeLa cells cultured on fibronectin-coated $\mathrm{R}$ 2/2 Quantifoil gold EM finder grids (Electron Microscopy
Sciences, USA) for cryo-EM was performed as described. ${ }^{31,32}$ Frozen grids were viewed under the FEI Tecnai G2 Spirit twin (FEI) at $120 \mathrm{kV}$ in cryo-conditions.

Pelleted cells were prepared for TEM as described. ${ }^{33,34}$ Ultrathin sections were cut using a Leica ultramicrotome (Leica, Austria) and post-stained with uranyl acetate and lead citrate. The grid was viewed under a Zeiss LEO912AB TEM (Carl Zeiss, Germany) at an accelerating voltage of $120 \mathrm{kV}$.

\section{Results and discussion}

\section{Synthesis and characterization of gold nanospheres}

A previous study reported a $35 \mathrm{~nm}$ depth threshold for nanotopographic patterns to influence cell behavior. ${ }^{35}$ It has been shown that the optimum size for AuNPs to enable accumulation on tumor tissues is $50-100 \mathrm{~nm} .^{36}$ Therefore, we chose 42,83 , and $111 \mathrm{~nm}$-wide, highly spherical, and monodispersed AuNSs to investigate the dependence of size on their biological effects. Often, AuNPs coated with stabilizers, including cetyl trimethyl ammonium bromide, ${ }^{37}$ tiopronin, ${ }^{38}$ fetal bovine serum, ${ }^{39}$ pol$\mathrm{y}$ (methacrylic acid), ${ }^{40}$ or polystyrene sulfonase, ${ }^{\mathbf{4 1}}$ are toxic to cells because of free molecules detaching from the AuNPs. Hence, we modified the initial AuNS surfaces with $\mathrm{NH}_{2}-\mathrm{PEG}-$ $\mathrm{SH}$; the PEG chain improves the dispersion of the AuNSs in buffer solution, and the $\mathrm{NH}_{2}$ group gives it a positive charge by ionization, ${ }^{42}$ enhancing interactions between the AuNSs and cells.

As shown by TEM of the $\mathrm{NH}_{2}$-PEG-modified AuNSs (NAuNSs) in Fig. 1A-C, all were ultra-smooth, highly spherical, and size-monodispersed. In several images, 100 particles were measured with ImageJ software. In Fig. 1D, the size distributions of N-AuNSs with $42 \pm 1.4,83 \pm 2.1$, and $111 \pm 2.4 \mathrm{~nm}$ diameters are shown. The highly monodispersed shape and size assist in measurement of size-dependent cellular responses without the interference caused by heterogeneous shapes. To calculate the concentration of the N-AuNSs stock solution, the absorbance in Fig. 1E was substituted into the Beer-Lambert equation with the extinction coefficient corresponding to the size indicated in a previous report. ${ }^{43}$ Each AuNS solution for the experiment was prepared to concentrations of $4.2 \times 10^{7}(\times 1)$, $2.1 \times 10^{9}(\times 50), 4.2 \times 10^{9}(\times 100)$, and $8.4 \times 10^{9}(\times 200) \mathrm{NSs}$ per $\mathrm{mL}$ by adding the necessary volume of cell culture medium into the stock solution (Table S2†).

\section{Effect of coating substrates on the in vitro cellular behavior of N-AuNSs}

We examined the in vitro behavior of N-AuNSs through electrostatic interactions with two oppositely charged cell culture coating substrates, fibronectin ${ }^{44}$ and poly-L-lysine, ${ }^{45}$ commonly used to promote cell attachment. Cells were plated onto fibronectin- and poly-L-lysine-coated EM gold grids and exposed to NAuNSs. As observed in cryo-EM images (Fig. 2A and B), the NAuNSs adhered to the fibronectin-coated surface and cultured cells concurrently, with active cellular interaction. In contrast, the N-AuNSs were hardly seen on the poly-L-lysine-coated surface or cells (Fig. 2C and D). 

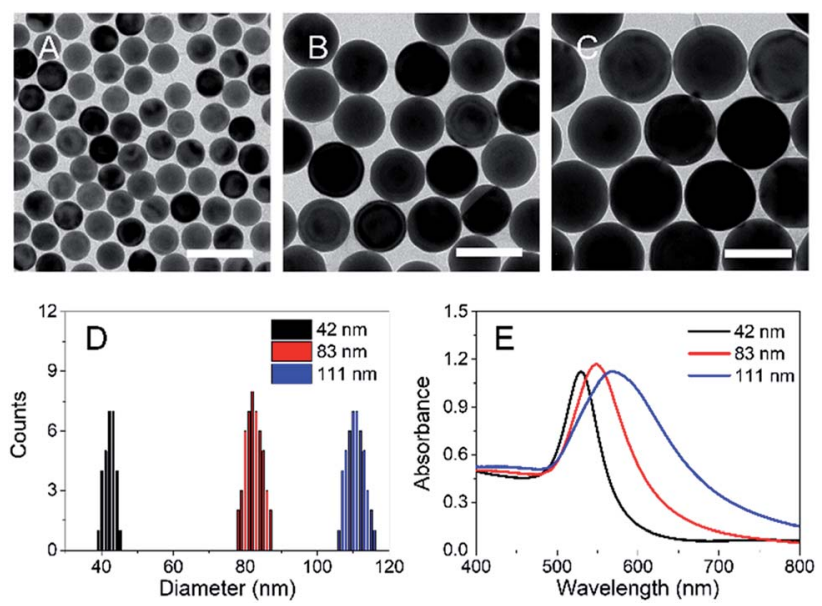

Fig. 1 Characterization of N-AuNSs. TEM images of N-AuNSs at (A) 42, (B) 83, and (C) $111 \mathrm{~nm}$. Scale bars, $100 \mathrm{~nm}$. (D) Size distribution and (E) UV/Vis absorption spectra of $\mathrm{N}$-AuNSs.

The fibronectin-coated EM grid facilitates N-AuNS interactions with cells because the positively charged AuNSs generally have a high affinity to the cells on the negatively charged fibronectin, inducing higher cellular uptake of N-AuNSs. In addition, N-AuNSs attached to the fibronectin-coated substrate produced heterogeneous colloidal nanotopographic features such as barriers within the extracellular space surrounding the HeLa cells. Thus, the surface charge of the coating substrates affects the cellular uptake of N-AuNSs and fibronectin can be utilized as an adequate coating reagent with N-AuNSs to produce in-plane nanobarriers for investigating HeLa cell
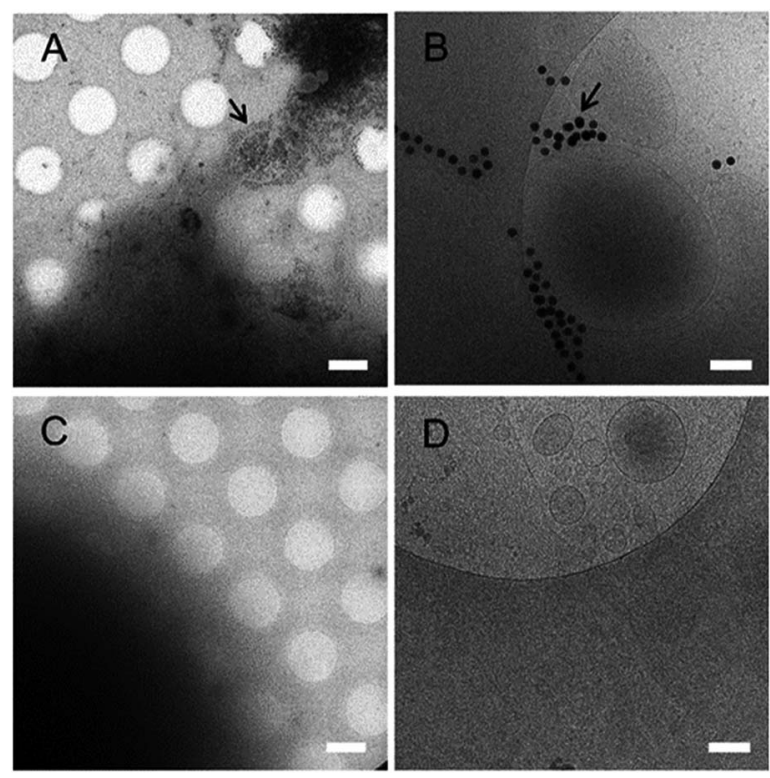

Fig. 2 Cryo-EM images of HeLa cells cultured on (A and B) human fibronectin and ( $C$ and D) poly-L-lysine-coated QUANTIFOIL gold EM grids and incubated with N-AuNSs $(42 \mathrm{~nm})$ for $24 \mathrm{~h}$. N-AuNSs are present in the fibronectin-coated grid (arrows), whereas only HeLa cells are observed in the poly-L-lysine-coated grid. Scale bars: (A and C) $2 \mu \mathrm{m}$; (B and D) $200 \mathrm{~nm}$. behavior in response to the extracellular biophysical cues and physicochemical properties of N-AuNSs. In further experiments, we used HeLa cells cultured in fibronectin-coated 96-well culture plates.

\section{Effect of N-AuNSs on cell proliferation}

The size- and concentration-dependent cytotoxicity of $\mathrm{N}$ AuNSs was evaluated using a CCK-8 cell proliferation assay. HeLa cells were cultured on fibronectin-coated 96-well culture plates and exposed to 42, 83, and $111 \mathrm{~nm} \mathrm{~N}$-AuNSs in increasing concentrations of $\times 1, \times 50, \times 100$, and $\times 200$ for $24 \mathrm{~h}$, since the cell-cycle duration of HeLa cells is approximately $22 \mathrm{~h}^{46}$ In this assay, $42 \mathrm{~nm} \mathrm{~N}$-AuNSs showed no significant influence on cell proliferation, independent of concentration (Fig. 3, black bar). The proliferation rate of cells exposed to $83 \mathrm{~nm} \mathrm{~N}$-AuNSs seemed to be unaffected at concentrations of $\times 1$. However, at 50 -fold higher concentrations cell proliferation decreased slightly, ranging from $73 \%$ to 79\% (Fig. 3, red bar). The presence of $111 \mathrm{~nm} \mathrm{N-AuNSs,}$ dramatically decreased cell proliferation in a concentrationdependent manner (Fig. 3, blue bar).

Cell proliferation is determined by the cycling behavior of cells, such as the speed of the cell cycle and the growth fraction (the population of actively cycling cells). ${ }^{47}$ Therefore, decreased cell proliferation may indicate delayed cell cycles or increased apoptosis. Overall, the cell proliferation rate seemed to be reduced in a size- and concentration-dependent manner only by $111 \mathrm{~nm}$ N-AuNSs (Fig. 3). Notably, a concentration of $\times 50$ was the inflection point at which significant changes in cell proliferation were detected for both 83 and $111 \mathrm{~nm} \mathrm{~N}$ AuNSs (Table S3†). Therefore, for closer investigation into the causes of this decreased cell proliferation, cells exposed to 42,83 , and $111 \mathrm{~nm} \mathrm{~N}$-AuNSs at concentrations of $\times 1$ and $\times 50$, were examined.

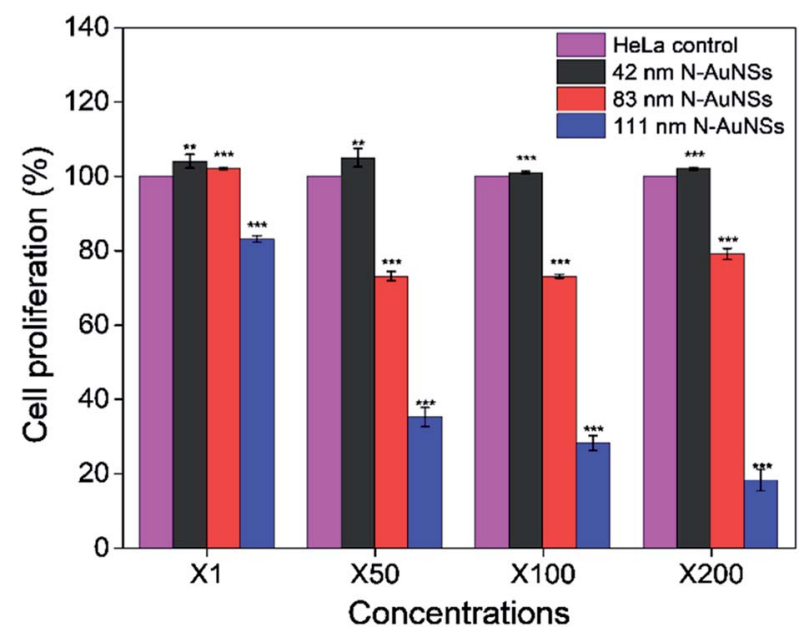

Fig. 3 Cell proliferation assessment of $\mathrm{N}$-AuNSs in HeLa cells using the CCK- 8 assay after $24 \mathrm{~h}$ exposure to 42,83 , and $111 \mathrm{~nm} \mathrm{~N}$-AuNSs at concentrations of $\times 1, \times 50, \times 100$, and $\times 200$. A significant decrease in HeLa cell proliferation was observed in the presence of $111 \mathrm{~nm} \mathrm{~N}$ AuNSs (error bars indicate standard errors; $n=4 ; * * P<0.01$, ***P< 0.001). 
A
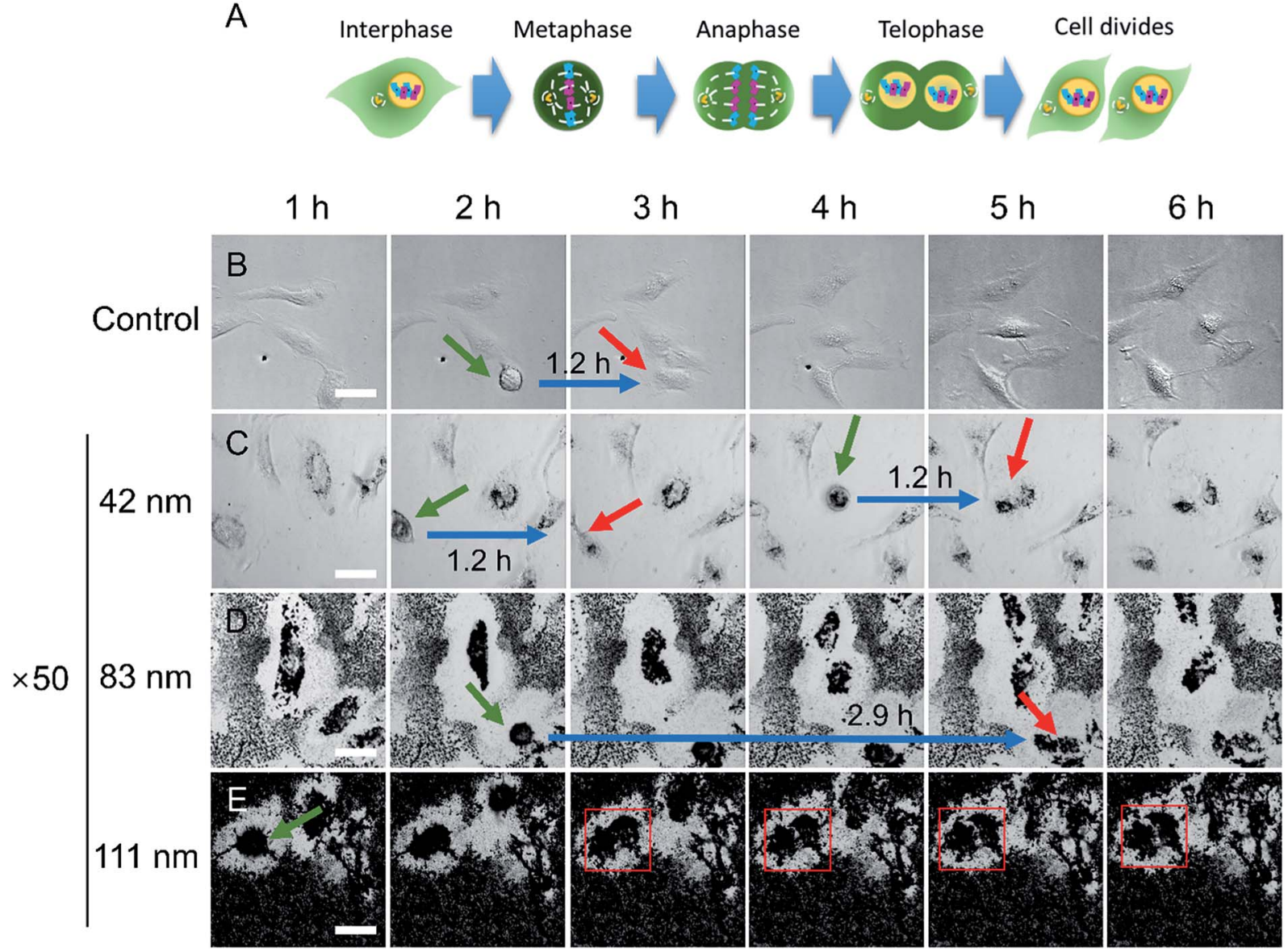

Fig. 4 (A) Schematic illustration of the M phase of the cell cycle. Time-lapse snapshots of (B) control and cells exposed to (C) 42, (D) 83, and (E) $111 \mathrm{~nm}$ N-AuNSs at $\times 50$ (refer to Videos S1-S4, $\uparrow$ respectively). The time points corresponding to each snapshot are indicated in the first row. Green arrows indicate the start point of metaphase and red arrows indicate the end point of telophase. The red square indicates cytokinesis arrest. Blue arrows indicate the times taken for $M$ phase. Scale bar, $50 \mu \mathrm{m}$.

\section{Cellular uptake of N-AuNSs in HeLa cells}

Bright-field optical microscopy images revealed the morphology of HeLa cells after $24 \mathrm{~h}$ of incubation with N-AuNSs. There were no differences in the number of cells among the control (untreated), 42, 83, or $111 \mathrm{~nm}$ spheres at a concentration of $\times 1$ (Fig. S3A-D $\dagger$ ). In contrast, similar to the cell proliferation results (Fig. 3), at a concentration of $\times 50$, decreases in cell numbers were observed for the 83 and $111 \mathrm{~nm} \mathrm{~N}$-AuNSs (Fig. S3G and $\mathrm{H} \dagger$ ), relative to the control and $42 \mathrm{~nm} \mathrm{~N}$-AuNSs-treated cells (Fig. S3E and $\mathrm{F}^{\dagger}$ ). As described above, N-AuNSs assemble on the fibronectin-coated substrate due to electrostatic attraction, forming a colloidal nanobarrier in the extracellular space. At a concentration of $\times 1$, the nanobarriers composed of 42 and $83 \mathrm{~nm}$ N-AuNSs were not observed (Fig. S3B and $\mathrm{C}^{\dagger}$ ), and few $111 \mathrm{~nm}$ N-AuNS clusters visible extracellularly (Fig. S3D†). At a concentration of $\times 50$, a clear colloidal nanobarrier was seen, although the nanotopographical density was very low for the $42 \mathrm{~nm}$ N-AuNSs (Fig. S3F $\dagger$ ). A denser nanobarrier was formed by $111 \mathrm{~nm}$ than $83 \mathrm{~nm} \mathrm{~N}$-AuNSs (Fig. S3G and $\mathrm{H}_{\dagger} \dagger$ ). As the $\times 50$ concentration $83 \mathrm{~nm}$ and $111 \mathrm{~nm}$ N-AuNSs-treated HeLa cells showed decreased proliferation rates, the nanobarrier might participate in the regulation of cell proliferation.
Cellular uptake and the precise localization of N-AuNSs were investigated by TEM. In previous reports, the cellular uptake of $\sim 50 \mathrm{~nm}$ AuNSs was noted as the most efficient. ${ }^{\mathbf{8 4 8 , 4 9}}$ However, in our case, all three sizes were internalized and localized in cytoplasmic vesicles (most likely endosomes or lysosomes) within $24 \mathrm{~h}$, showing that the particle size does not affect the cellular uptake of N-AuNSs under our experimental conditions (Fig. S4†). Penetration of N-AuNSs into nuclei was not observed; therefore, DNA damage induced by nuclear internalization of nanoparticles is unlikely to contribute to decreased cell proliferation. Moreover, the sizes of the particle-loaded vesicles seemed to increase with increasing $\mathrm{N}$-AuNS size. Fig. $\mathrm{S} 4 \mathrm{H} \dagger$ shows endosomes up to $1 \mu \mathrm{m}$ in diameter. Increases in endosomal size enhance endosomal escape $;^{50}$ therefore, it might be important to know that endosomes are generated according to nanoparticle size for efficient drug delivery systems.

\section{Cell cycle regulation by $\mathrm{N}$-AuNSs}

As shown in Fig. 3, the cell proliferation assay results for HeLa cells exposed to N-AuNSs at a concentration of $\times 50$ and $\times 1$ showed no difference for the $42 \mathrm{~nm}$ N-AuNSs, but displayed approximately $73 \%$ and $35 \%$ less proliferation at $\times 50$ for the 
$83 \mathrm{~nm}$ and $111 \mathrm{~nm}$ N-AuNSs, respectively. To evaluate cell cycle arrest, which influences the rate of cell proliferation, live-cell imaging of HeLa cells exposed to 42, 83, and $111 \mathrm{~nm} \mathrm{~N}$-AuNSs at concentrations of $\times 1$ and $\times 50$ was performed for $24 \mathrm{~h}$. The first six images, taken at $1 \mathrm{~h}$ intervals, of the $\times 50$ concentration treatments are displayed in Fig. 4 (Video S1-S4†). This imaging revealed that the fabrication of the nanobarrier with N-AuNSs occurs very quickly; N-AuNSs sedimentation reached its saturation point within the first hour of exposure (Fig. 4; Video S2$\mathrm{S} 4 \dagger)$.

A typical cell cycle consists of $\mathrm{G} 1, \mathrm{~S}, \mathrm{G} 2$, and $\mathrm{M}$ phases. ${ }^{25}$ Here, we focused on $\mathrm{M}$ phase, in which dynamic changes in cell morphology, such as cell rounding, and the final physical cell division (cytokinesis) are observed. ${ }^{51} \mathrm{M}$ phase is divided into a series of shorter phases including metaphase and telophase (Fig. 4A). In metaphase, the cells undergo mitotic cell rounding and in telophase, the cleavage furrow begins to form. ${ }^{51}$ In this study, by setting metaphase (green arrow) as a start-point and telophase (red arrow) as an endpoint, the duration of the $\mathbf{M}$ phase was measured to assess cell-cycle transit time (Fig. 4B-E).

The M-phase durations of control cells and cells treated with $42 \mathrm{~nm}$ N-AuNSs at $\times 50$ concentration were identical at $1.2 \mathrm{~h}$. However, the M-phase duration of cells incubated with $83 \mathrm{~nm}$ $\mathrm{N}$-AuNSs was 2.4 times more than that of control and the $42 \mathrm{~nm}$ $\mathrm{N}$-AuNS-treated cells. Despite a prolonged $\mathrm{M}$ phase, mitosis and cytokinesis were completed (Video S3†); the cells-initiated cytokinesis with mitotic cell rounding, followed by contractile ring constriction, concomitant cleavage furrow ingression, the extension of a cytoplasmic bridge linking the two daughter cells, and finally, complete abscission. In contrast, cytokinesis arrest was observed in cells incubated with $111 \mathrm{~nm} \mathrm{N-AuNSs} \mathrm{(Fig.} \mathrm{4E);}$ cytokinesis began with mitotic cell rounding, but the extension of the cytoplasmic bridge did not occur (red square), and daughter cells did not separate over $24 \mathrm{~h}$. At a concentration of $\times 50$, it is likely that $83 \mathrm{~nm} \mathrm{~N}$-AuNSs slowed the $M$ phase of the cell cycle, while $111 \mathrm{~nm}$ N-AuNSs inhibited cells from completing cell division.

To further investigate the arrest of cytokinesis, cell-cycle analyses on cells exposed to $83 \mathrm{~nm}$ and $111 \mathrm{~nm}$ N-AuNSs at $\times 1$ and $\times 50$ were performed using flow cytometry (Fig. 5 ). The cell-cycle stage distribution of control cells was comparable to that of cells exposed to $83 \mathrm{~nm} \mathrm{~N}$-AuNSs at a concentration of $\times 1$. At a concentration of $\times 50,83 \mathrm{~nm} \mathrm{~N}$-AuNSs increased the percentage of cells in G2/M phase. G2/M-phase arrest induced by AuNPs has been observed in conjunction with high cytotoxicity, suggested by high levels of ROS. ${ }^{\mathbf{4 0 5 2}}$ Moreover, cell-cycle arrest can occur temporarily for maintenance purposes to dissipate an exogenous cellular stress signal, to repair cellular damage, or to provide essential growth factors. ${ }^{53}$ In the presence of $83 \mathrm{~nm} \mathrm{~N}$-AuNSs at $\times 50$, a low sub-G1 cell population (apoptotic cells) was observed, suggesting that the process of cell division had been slowed, but did not lead to apoptosis (Fig. 5).

Cytokinesis arrest could result in apoptosis. ${ }^{54,55}$ Flow cytometry showed that the sub-G1-phase population increased with increasing concentration in the presence of $111 \mathrm{~nm} \mathrm{~N}$ AuNSs (Fig. 5). These size- and concentration-dependent

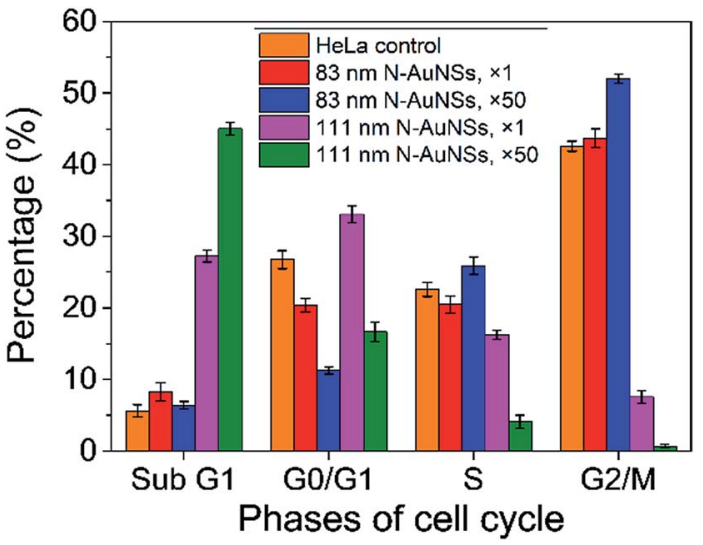

Fig. 5 Cell cycle analysis of HeLa cells exposed to 83 and $111 \mathrm{~nm} \mathrm{~N}$ AuNSs at $\times 1$ and $\times 50$ for $24 \mathrm{~h}$. The graph represents G2/M phase arrest in HeLa cells exposed to $83 \mathrm{~nm} \mathrm{~N}$-AuNSs at $\times 50$ and the percentages of cells in the sub-G1 phase in the presence of $111 \mathrm{~nm} \mathrm{~N}$ AuNSs, suggesting apoptosis (error bars indicate standard errors).

characteristics of $111 \mathrm{~nm} \mathrm{~N}$-AuNS-induced apoptosis were similar to the decreasing proliferation rates of cells treated with $111 \mathrm{~nm} \mathrm{~N}$-AuNSs (Fig. 3). At concentrations of $\times 50$, it is obvious that $111 \mathrm{~nm} \mathrm{N-AuNSs}$ caused cytokinesis arrest in HeLa cells (Fig. 4E), leading to apoptotic cell death (Video S5†) and decreasing cell proliferation.

\section{Mitochondrial ROS generation induced by N-AuNSs}

Most cell damage in AuNPs studies has been attributed to induced ROS modulating cellular processes including cell proliferation, cell cycle progression, cell death, cell cycle arrest, and alterations in apoptosis. ${ }^{\mathbf{1 2 , 4 0}}$ The AuNSs used in our experiment were surface-modified with $\mathrm{NH}_{2}-\mathrm{PEG}$, whose amine group had been previously shown to damage mitochondria. ${ }^{56}$ As mitochondria are the major source of cellular ROS, ${ }^{57}$ evaluation of cytotoxicity caused by the amine group was focused on mitochondrial ROS production. To determine whether ROS generation and DNA damage were caused by the functional group of the N-AuNSs, fluorescence assays with NucBlue and MitoSOX reagents were performed on cells treated with 83 and $111 \mathrm{~nm}$ N-AuNSs at concentrations of $\times 1$ and $\times 50$. As shown in the optical images in Fig. 6A and B, cells exposed to $83 \mathrm{~nm} \mathrm{~N}$ AuNSs exhibited intact and homogenous cell nuclei stained by NucBlue, indicating no nuclear DNA damage. Among cells exposed to $111 \mathrm{~nm}$ N-AuNSs, a few showed lower signal intensities than others (arrows in Fig. 6C) or no NucBlue signal (Fig. 6D). This suggests that DNA degradation might be in progress, inducing apoptosis. ${ }^{58}$ The nuclei exhibited a purple color in the overlay image (arrowheads in Fig. 6D) due to nuclear staining by MitoSOX, indicating a loss of mitochondrial structure or membrane potential in dying cells. ${ }^{59}$ In accordance with the NucBlue results, the MitoSOX signal, which is induced by mitochondrial ROS, was detected only in cells exposed to the $111 \mathrm{~nm}$ N-AuNSs at both concentrations. Moreover, in the TEM image shown in Fig. S5, $\dagger$ enlarged lysosomes and accumulation of autophagosomes were seen with $111 \mathrm{~nm} \mathrm{N-AuNSs}$; these are 


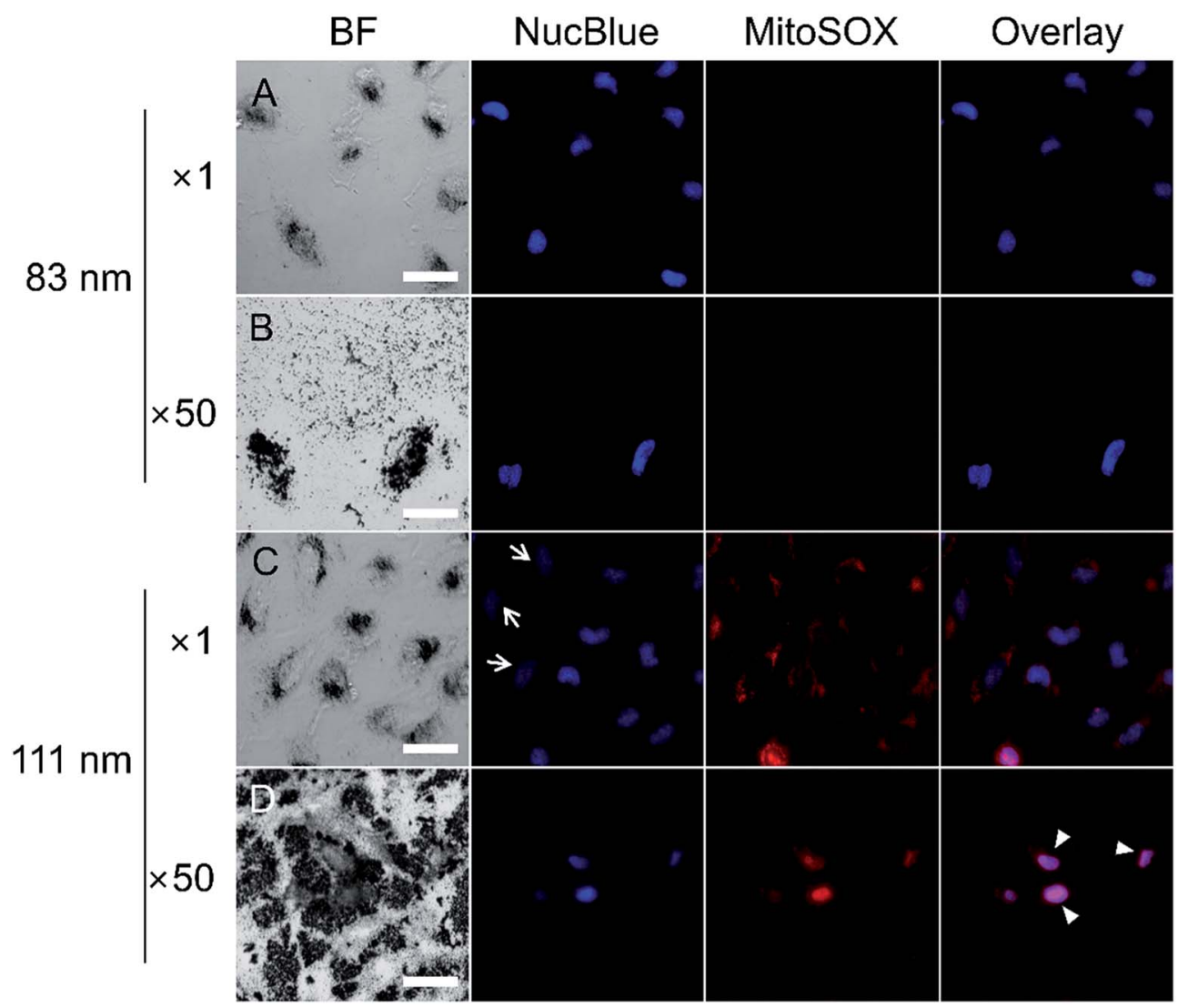

Fig. 6 Fluorescence microscopy determination of mitochondrial ROS generation in HeLa cells after $24 \mathrm{~h}$ treatment with (A and B) $83 \mathrm{~nm}$ and (C and D) $111 \mathrm{~nm} \mathrm{N-AuNSs.} \mathrm{In} \mathrm{the} \mathrm{presence} \mathrm{of} 83 \mathrm{~nm} \mathrm{~N}$-AuNSs at (A) $\times 1$ and (B) $\times 50$, mitochondrial ROS (MitoSOX) were not detected in HeLa cells, whereas $111 \mathrm{~nm} \mathrm{~N}$-AuNSs at (C) $\times 1$ and (D) $\times 50$ induced the generation of mitochondrial ROS (MitoSOX). Bright field (BF; leftmost), NucBlue (second from the left), MitoSOX (second from the right), and overlay (rightmost) display cell morphology, living cell nuclei, mitochondrial ROS generation, and merged fluorescence images, respectively. Arrows indicate low NucBlue intensity and arrowheads indicate nuclear staining of MitoSOX. Scale bar, $50 \mu \mathrm{m}$.

cellular defense mechanisms against oxidative stress. ${ }^{34}$ Finally, to evaluate the inductive relationship between the functional amine group and ROS generation, the number of amine groups on the 83 and $111 \mathrm{~nm} \mathrm{N-AuNS}$ surfaces were calculated from a GaussAmp curve of fluorescein isothiocyanate (FITC) solution. As shown in Table S1, $\uparrow$ the numbers of PEG molecules on the 83 and $111 \mathrm{~nm}$ N-AuNS surfaces were measured to $2.62 \times 10^{3}$ and $4.73 \times 10^{3}$ PEG/AuNS, respectively, similar to the reported number of PEG molecules on similar-sized AuNPs. ${ }^{60}$

Despite the fact that the number of amine groups on the $83 \mathrm{~nm} \mathrm{~N}$-AuNSs at $\times 50$ was $2.3 \times 10^{8}$ times higher than that on the $111 \mathrm{~nm}$ N-AuNSs at $\times 1$ (Table S1 $\dagger$ ), mitochondrial ROS was not detected with $83 \mathrm{~nm} \mathrm{~N}$-AuNSs at $\times 50$. Based on the association between the amine number and dye signal, we could conclude that the amine group is irrelevant to ROS production, but that $111 \mathrm{~nm}$ N-AuNSs play a significant role in ROS production, consequently inducing apoptosis.

\section{Biophysical effects of N-AuNS nanobarriers on HeLa cells}

Because $83 \mathrm{~nm}$ N-AuNSs were irrelevant to ROS generation, it was necessary to further investigate what factors influenced cellcycle prolongation. Some studies have reported that physical restriction of cell movement, such as a hydrogel 3D cell culture or nanotopography, can influence the cell cycle. ${ }^{24,61-63}$ Therefore, we focused on physical interactions between the cells and the nanobarriers. We repeated the live cell imaging of HeLa cells with 42 and $83 \mathrm{~nm}$ N-AuNSs under the same conditions as above, but in 4-chamber dishes. As the $298 \mathrm{~mm}^{2}$ bottom surface area of a chamber in a 4-chamber dish is approximately 10 times larger than that of a well in a 96-well plate, it results in a more sparse nanobarrier (Fig. S6 $\dagger$ ). The M-phase duration of the cells cultured in the 4 -chamber dishes with $42 \mathrm{~nm}$ N-AuNSs at $\times 1$ and $\times 50$ and $83 \mathrm{~nm} \mathrm{~N}$-AuNSs at $\times 1$ was $1.1 \mathrm{~h}$, similar to the time in the 96-well plate. However, the mean duration of the M phase with $83 \mathrm{~nm}$ N-AuNSs at $\times 50$ was $1.3 \mathrm{~h}$, much shorter than the $2.9 \mathrm{~h}$ observed under the same conditions in the 96-well plate, but slightly longer than that of the other conditions in the chamber. In this experiment, the only difference in the environment was the surface area of the cell-culture wells. Therefore, we calculated the coverage of N-AuNSs on the plates to elucidate the role of N-AuNSs in the external space around the cells.

In calculating N-AuNSs coverage, we confirmed two factors from the TEM image in Fig. 7; (1) the N-AuNSs are randomly distributed and (2) they form a monolayer. The coverage of $\mathrm{N}$ AuNSs on the bottom of the cell culture plate was calculated 

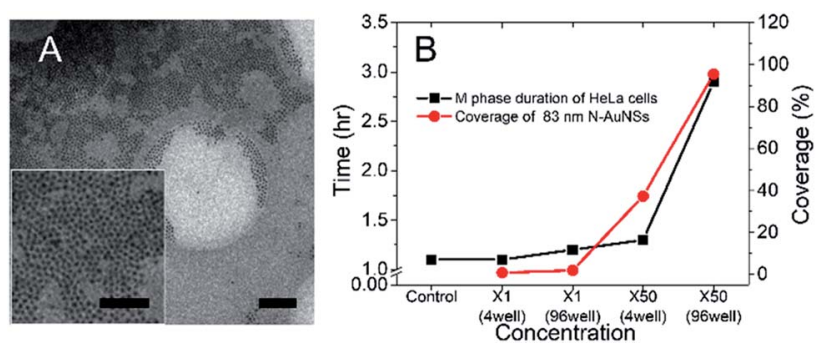

Fig. 7 (A) Cryo-EM image of randomly distributed N-AuNSs on the fibronectin-coated substrate. The inset is a higher-magnification image of the monolayer. Scale bars: (A) $1 \mu \mathrm{m} ; 500 \mathrm{~nm}$ in the inset of (A). (B) $M$ phase duration and calculated coverages of $83 \mathrm{~nm} \mathrm{~N}$-AuNSs at $\times 1$ and $\times 50$ in a 4-chamber dish and 96 -well plate.

(eqn (2)) (2) by dividing the total cross-sectional area of the $\mathrm{N}$ AuNSs by the bottom area of the cell culture plate and the random packing fraction:

$$
C=\frac{A_{\mathrm{Au}}}{A_{\mathrm{M}}}=\frac{\pi r_{\mathrm{Au}}^{2} N_{\mathrm{Au}}}{\pi r_{\mathrm{P}}^{2} \varphi}
$$

here $C$ is the coverage of N-AuNSs on the bottom of the cell culture plate, $A_{\mathrm{Au}}$ is the total cross-section area of N-AuNSs, $r_{\mathrm{Au}}$ is the radius of the N-AuNS, $N_{\mathrm{Au}}$ is the total number of $\mathrm{N}$-AuNSs, $A_{\mathrm{M}}$ is the surface area of the cell culture plate available for N-AuNSs monolayer coverage, $r_{\mathrm{P}}$ is the radius of the bottom of the cell culture plate, and $\varphi$ is the randompacking fraction in two dimensions $(0.82){ }^{64}$ The calculated $83 \mathrm{~nm}$ N-AuNSs coverage in the 4-chamber dish and 96-well plate is plotted in Fig. 7B. The coverage in the 4-chamber dish and 96 -well plate at $\times 1$ was calculated as $0.7 \%$ and $1.9 \%$, respectively. However, when the concentration was increased to $\times 50$, the coverage of $83 \mathrm{~nm} \mathrm{~N}$-AuNSs soared to 37 and $96 \%$ in the 4-chamber dish and 96-well plate, respectively (see in Fig. S7A and $B \dagger$ ). This tendency reveals that the duration of the $\mathrm{M}$ phase in the HeLa cell cycle is proportional to N-AuNS coverage, although the time did not extend at concentrations over $\times 50$ with the $83 \mathrm{~nm}$ N-AuNSs in the 96 -well plate. This close relationship suggests that physical nanotopographic cues of the nanobarrier arrested cell cycle progression in the $\mathrm{M}$ phase, and eventually reduced cell proliferation. Cells are known to require sufficient growth area to for successful progression through the $\mathrm{M}$ phase. ${ }^{25,65}$ We hypothesize that when cells are more constricted by the N-AuNSs, they need more time to secure this growth area. As a supporting evidence, Video $\mathrm{S} 3 \uparrow$ and the schematic in Fig. 8A show that cell division progresses after an N-AuNSs-absent growth area is secured by the uptake of the nanoparticles on the substrate by filopodia. Interactions between filopodia and nanoparticles have been described in several previous reports. ${ }^{66-68}$ The growth area surrounding the cell membrane was easily detectable (Fig. 8B) and multiple filopodia interacting with NAuNSs were observed by cryo-EM (Fig. 8C and E) and SEM (Fig. 8D).

When using $42 \mathrm{~nm}$ N-AuNSs, cell proliferation was similarly maintained even at $\times 200$ in the 96 -well plates (Fig. S7C $\dagger$ ), although the coverage was $98 \%$, larger than that of the $83 \mathrm{~nm}$ $\mathrm{N}$-AuNSs at $\times 50(95 \%)$. Despite the higher coverage, the constant length of the $M$ phase indicates that a specific nanoparticle size causes to phase arrest. Nanostructured surfaces have been reported to regulate multiple cell responses including cell locomotion, ${ }^{20}$ spreading, ${ }^{21}$ differentiation, ${ }^{22}$ adhesion, ${ }^{23}$ and cell cycle progression. ${ }^{24}$ Interestingly, this study revealed a novel effect of AuNSs through electrostatic deposition of positively charged N-AuNSs on a oppositely charged substrate; $42 \mathrm{~nm}$ N-AuNSs had no effect on the cell cycle at any concentration, $83 \mathrm{~nm}$ N-AuNSs increased the duration of $\mathrm{M}$ phase to 2.4 times higher than that of control cells, and $111 \mathrm{~nm} \mathrm{N-AuNSs} \mathrm{drove} \mathrm{HeLa} \mathrm{cells} \mathrm{to} \mathrm{apoptosis} \mathrm{even}$ at $\times 1$ concentrations.

\section{A}

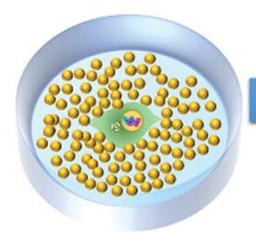

Fabrication of nanobarrier with N-AuNSs (positive charge) on the substrate (negative charge)

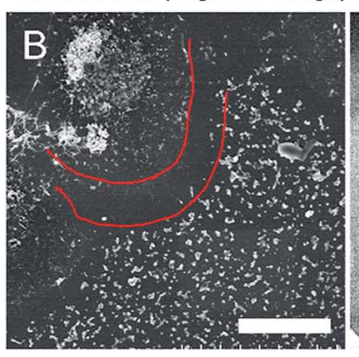

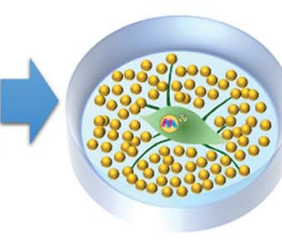

Filopodia eliminates $\mathrm{N}$-AuNSs to secure growth area

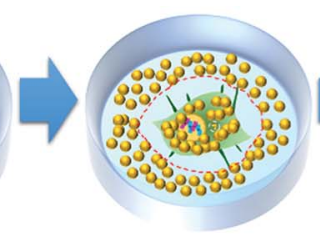

When growth area is secured, cell can proceed through $\mathrm{M}$ phase

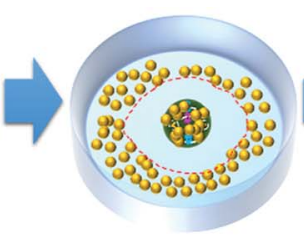

Prolongation of $\mathrm{M}$ phase

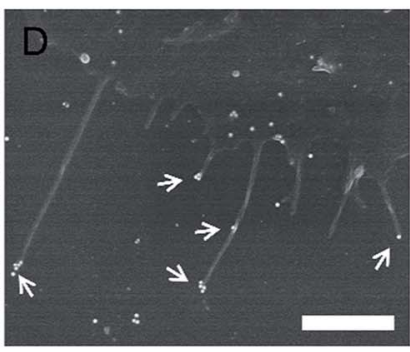

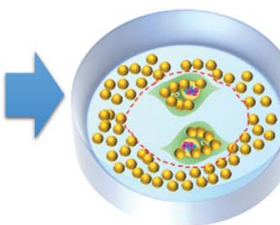

Complete cell division without major cell damage
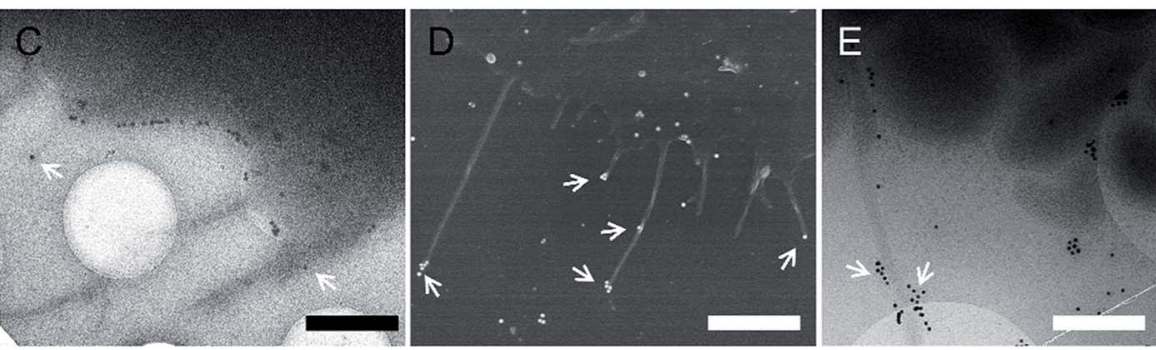

Fig. 8 (A) Schematic of cell division in the presence of nanobarriers. (B) Nanobarrier-absent growth area was confirmed by SEM. Red lines indicate cell borders and nanobarrier. Adhesion of N-AuNSs to filopodia (white arrows) was viewed by (C) and (E) cryo-EM and (D) SEM. Scale bars: (B) $20 \mu \mathrm{m}$; (C) $5 \mu \mathrm{m}$; (D) $2 \mu \mathrm{m}$; (E) $500 \mathrm{~nm}$. 


\section{Conclusions}

We have demonstrated particle size- and concentrationdependent effects of an engineered nanobarrier on the proliferation of HeLa cells cultured on a fibronectin-coated substrate. The nanobarrier was made up of AuNSs, which allowed the experimental results to be interpreted with respect to only particle size and concentration. The $\mathrm{NH}_{2}-\mathrm{PEG}-\mathrm{SH}$ on the AuNSs led to electrostatic deposition on the fibronectin-coated substrate and active interaction with cells. During cellular uptake, the size of the N-AuNSs-loaded endocytic vesicles increased with both increasing particle concentration and size. The cytotoxicity assessment showed changes in the proliferation of HeLa cells caused by N-AuNSs. The physicochemical and biophysical assays indicated that $111 \mathrm{~nm} \mathrm{~N}$-AuNSs induced ROS generation, cytokinesis arrest, and apoptosis in HeLa cells. Meanwhile, a dense nanobarrier composed of $83 \mathrm{~nm} \mathrm{~N}$-AuNSs on the substrate physically restricted the growth area around the cell and induced a prolonged $\mathbf{M}$ phase without inducing apoptosis or ROS production. This indicates that the specific nanoparticle size served as a suitable nanobarrier leading to cell-cycle phase arrest. Our results suggest that using N-AuNSs and fibronectin-coated substrates is an easy and inexpensive way to fabricate colloidal nanobarriers for biological investigations, and this could be a novel biotechnical platform to adjust cell cycle progression without causing unintended damage, such as apoptosis, which may interrupt the goal of the study. Furthermore, despite our results were limited in in vitro experiment, future experiment on in vivo application of N-AuNSs to test their efficiency in cancer study could expect interesting effect of gold nanoparticles including NanoEL effect. ${ }^{69-71}$

\section{Conflicts of interest}

There are no conflicts to declare.

\section{Acknowledgements}

This work was supported by the Korea Basic Science Institute Fund (D39614) and a National Research Council of Science \& Technology grant from the Korean government (CRC-16-01KRICT) and the National Research Foundation of Korea (NRF2014M3A9B8023471).

\section{Notes and references}

1 R. Toy, P. M. Peiris, K. B. Ghaghada and E. Karathanasis, Nanomedicine, 2014, 9, 121-134.

2 A. J. Cobley, T. J. Mason, M. Alarjah, R. Ashayer and S. H. Mannan, Ultrason. Sonochem., 2011, 18, 37-41.

3 D. Astruc, E. Boisselier and C. Ornelas, Chem. Rev., 2010, 110, 1857-1959.

4 D. Movia, V. Gerard, C. M. Maguire, N. Jain, A. P. Bell, V. Nicolosi, T. O'Neill, D. Scholz, Y. Gun'ko, Y. Volkov and A. Prina-Mello, Biomaterials, 2014, 35, 2543-2557.

5 I. Fratoddi, I. Venditti, C. Cametti and M. V. Russo, Toxicol. Res., 2015, 4, 796-800.
6 M. Hu, L. Qian, R. P. Brinas, E. S. Lymar, L. Kuznetsova and J. F. Hainfeld, J. Struct. Biol., 2008, 161, 83-91.

7 S. Ruan, M. Yuan, L. Zhang, G. Hu, J. Chen, X. Cun, Q. Zhang, Y. Yang, Q. He and H. Gao, Biomaterials, 2015, 37, 425-435.

8 B. D. Chithrani, A. A. Ghazani and W. C. Chan, Nano Lett., 2006, 6, 662-668.

9 E. C. Cho, Q. Zhang and Y. Xia, Nat. Nanotechnol., 2011, 6, 385-391.

10 N. M. Schaeublin, L. K. Braydich-Stolle, A. M. Schrand, J. M. Miller, J. Hutchison, J. J. Schlager and S. M. Hussain, Nanoscale, 2011, 3, 410-420.

11 D. Choudhury, P. L. Xavier, K. Chaudhari, R. John, A. K. Dasgupta, T. Pradeep and G. Chakrabarti, Nanoscale, 2013, 5, 4476-4489.

12 V. Ramalingam, S. Revathidevi, T. Shanmuganayagam, L. Muthulakshmi and R. Rajaram, $R S C A d v ., 2016,6$, 20598-20608.

13 X. Huang, X. Teng, D. Chen, F. Tang and J. He, Biomaterials, 2010, 31, 438-448.

14 F. Etoc, D. Lisse, Y. Bellaiche, J. Piehler, M. Coppey and M. Dahan, Nat. Nanotechnol., 2013, 8, 193-198.

15 B. Kim, G. Han, B. J. Toley, C. K. Kim, V. M. Rotello and N. S. Forbes, Nat. Nanotechnol., 2010, 5, 465-472.

16 K. Saha, S. S. Agasti, C. Kim, X. Li and V. M. Rotello, Chem. Rev., 2012, 112, 2739-2779.

17 X. Q. Liu and R. Z. Tang, Drug Delivery, 2017, 24, 1-15.

18 X. Shi, Y. Wang, D. Li, L. Yuan, F. Zhou, Y. Wang, B. Song, Z. Wu, H. Chen and J. L. Brash, Langmuir, 2012, 28, 1701117018.

19 V. L. Lapointe, A. T. Fernandes, N. C. Bell, F. Stellacci and M. M. Stevens, Adv. Healthcare Mater., 2013, 2, 1644-1650.

20 D. C. Miller, A. Thapa, K. M. Haberstroh and T. J. Webster, Biomaterials, 2004, 25, 53-61.

21 K. Amschler, L. Erpenbeck, S. Kruss and M. P. Schon, ACS Nano, 2014, 8, 9113-9125.

22 Q. Huang, T. A. Elkhooly, X. Liu, R. Zhang, X. Yang, Z. Shen and Q. Feng, Colloids Surf., B, 2016, 145, 37-45.

23 J. Fiedler, B. Ozdemir, J. Bartholoma, A. Plettl, R. E. Brenner and P. Ziemann, Biomaterials, 2013, 34, 8851-8859.

24 L. C. Lee, N. Gadegaard, M. C. de Andres, L. A. Turner, K. V. Burgess, S. J. Yarwood, J. Wells, M. SalmeronSanchez, D. Meek, R. O. Oreffo and M. J. Dalby, Biomaterials, 2017, 116, 10-20.

25 B. Alberts, A. Johnson, J. Lewis, M. Raff and a. P. W. Keith Roberts, An overview of $M$ phase, Garland Science, New York, 4th edn., 2002.

26 K. S. Chan, C. G. Koh and H. Y. Li, Cell Death Discovery, 2012, 3, e411.

27 Y. Stroikin, H. Dalen, U. T. Brunk and A. Terman, Biogerontology, 2005, 6, 39-47.

28 E. Manchado, M. Guillamot and M. Malumbres, Cell Death Differ., 2012, 19, 369-377.

29 S. Senese, Y. C. Lo, D. Huang, T. A. Zangle, A. A. Gholkar, L. Robert, B. Homet, A. Ribas, M. K. Summers, M. A. Teitell, R. Damoiseaux and J. Z. Torres, Cell Death Discovery, 2014, 5, e1462. 
30 Y. J. Lee, N. B. Schade, L. Sun, J. A. Fan, D. R. Bae, M. M. Mariscal, G. Lee, F. Capasso, S. Sacanna, V. N. Manoharan and G. R. Yi, ACS Nano, 2013, 7, 1106411070.

31 S. Jun, D. Ke, K. Debiec, G. Zhao, X. Meng, Z. Ambrose, G. A. Gibson, S. C. Watkins and P. Zhang, Structure, 2011, 19, 1573-1581.

32 S. Jun, G. Zhao, J. Ning, G. A. Gibson, S. C. Watkins and P. Zhang, J. Visualized Exp., 2013, 76, e50386.

33 H. J. Ro, H. Lee, E. C. Park, C. S. Lee, S. Il Kim and S. Jun, Sci. Rep., 2018, 8, 17373.

34 S. H. Yun, S. Y. Lee, C. W. Choi, H. Lee, H. J. Ro, S. Jun, Y. M. Kwon, K. K. Kwon, S. J. Kim, G. H. Kim and S. I. Kim, J. Microbiol., 2017, 55, 56-62.

35 W. A. Loesberg, J. te Riet, F. C. van Delft, P. Schon, C. G. Figdor, S. Speller, J. J. van Loon, X. F. Walboomers and J. A. Jansen, Biomaterials, 2007, 28, 3944-3951.

36 K. Greish, J. Drug Targeting, 2007, 15, 457-464.

37 H. Takahashi, Y. Niidome, T. Niidome, K. Kaneko, H. Kawasaki and S. Yamada, Langmuir, 2006, 22, 2-5.

38 L. Cui, P. Zahedi, J. Saraceno, R. Bristow, D. Jaffray and C. Allen, Nanomedicine, 2013, 9, 264-273.

39 J. J. Li, D. Hartono, C. N. Ong, B. H. Bay and L. Y. Yung, Biomaterials, 2010, 31, 5996-6003.

40 S. J. Soenen, B. Manshian, J. M. Montenegro, F. Amin, B. Meermann, T. Thiron, M. Cornelissen, F. Vanhaecke, S. Doak, W. J. Parak, S. De Smedt and K. Braeckmans, ACS Nano, 2012, 6, 5767-5783.

41 Z. Fan, X. Yang, Y. Li, S. Li, S. Niu, X. Wu, J. Wei and G. Nie, Biointerphases, 2012, 7, 10.

42 X. Gao, G. Xu, Y. Zhao, S. Li, F. Shi and Y. Chen, RSC Adv., 2015, 5, 88045-88051.

43 D. K. Kim, Y. J. Hwang, C. Yoon, H. O. Yoon, K. S. Chang, G. Lee, S. Lee and G. R. Yi, Phys. Chem. Chem. Phys., 2015, 17, 20786-20794.

44 C. R. Wittmer, J. A. Phelps, W. M. Saltzman and P. R. Van Tassel, Biomaterials, 2007, 28, 851-860.

45 W. L. McKeehan and R. G. Ham, J. Cell Biol., 1976, 71, 727734.

46 J. W. Posakony, J. M. England and G. Attardi, J. Cell Biol., 1977, 74, 468-491.

47 R. Eidukevicius, D. Characiejus, R. Janavicius, N. Kazlauskaite, V. Pasukoniene, M. Mauricas and W. Den Otter, BMC Cancer, 2005, 5, 122.

48 X. Liu, N. Huang, H. Li, Q. Jin and J. Ji, Langmuir, 2013, 29, 9138-9148.

49 K. Niikura, T. Matsunaga, T. Suzuki, S. Kobayashi, H. Yamaguchi, Y. Orba, A. Kawaguchi, H. Hasegawa, K. Kajino, T. Ninomiya, K. Ijiro and H. Sawa, ACS Nano, 2013, 7, 3926-3938.
50 L. M. P. Vermeulen, T. Brans, S. K. Samal, P. Dubruel, J. Demeester, S. C. De Smedt, K. Remaut and K. Braeckmans, ACS Nano, 2018, 12, 2332-2345.

51 C. J. Cattin, M. Duggelin, D. Martinez-Martin, C. Gerber, D. J. Muller and M. P. Stewart, Proc. Natl. Acad. Sci. U. S. A., 2015, 112, 11258-11263.

52 J. J. Li, L. Zou, D. Hartono, C. N. Ong, B. H. Bay and L. Y. Lanry Yung, Adv. Mater., 2008, 20, 138-142.

53 M. Uz, V. Bulmus and S. Alsoy Altinkaya, Langmuir, 2016, 32, 5997-6009.

54 B. Kang, M. A. Mackey and M. A. El-Sayed, J. Am. Chem. Soc., 2010, 132, 1517-1519.

55 J. D. Orth, A. Loewer, G. Lahav and T. J. Mitchison, Mol. Biol. Cell, 2012, 23, 567-576.

56 D. Edmondson, Curr. Pharm. Des., 2014, 20, 155-160.

57 C. Richter, Int. J. Biochem. Cell Biol., 1995, 27, 647-653.

58 R. Mandelkow, D. Gumbel, H. Ahrend, A. Kaul, U. Zimmermann, M. Burchardt and M. B. Stope, Anticancer Res., 2017, 37, 2239-2244.

59 P. Mukhopadhyay, M. Rajesh, G. Hasko, B. J. Hawkins, M. Madesh and P. Pacher, Nat. Protoc., 2007, 2, 2295-2301.

60 S. J. Hurst, A. K. Lytton-Jean and C. A. Mirkin, Anal. Chem., 2006, 78, 8313-8318.

61 J. Z. Gasiorowski, S. J. Liliensiek, P. Russell, D. A. Stephan, P. F. Nealey and C. J. Murphy, Biomaterials, 2010, 31, 88828888.

62 S. J. Liliensiek, J. A. Wood, J. Yong, R. Auerbach, P. F. Nealey and C. J. Murphy, Biomaterials, 2010, 31, 5418-5426.

63 M. Aragona, T. Panciera, A. Manfrin, S. Giulitti, F. Michielin, N. Elvassore, S. Dupont and S. Piccolo, Cell, 2013, 154, 10471059.

64 J. G. Berryman, Phys. Rev. A, 1983, 27, 1053-1061.

65 A. I. Goranov, M. Cook, M. Ricicova, G. Ben-Ari, C. Gonzalez, C. Hansen, M. Tyers and A. Amon, Genes Dev., 2009, 23, 1408-1422.

66 L. Pauksch, M. Rohnke, R. Schnettler and K. S. Lips, Toxicol. Rep., 2014, 1, 900-908.

67 K. Tzelepi, C. Espinosa Garcia, P. Williams and J. Golding, Nanoscale Adv., 2019, 1, 807-816.

68 Y. Qin, K. Chen, W. Gu, X. Dong, R. Lei, Y. Chang, X. Bai, S. Xia, L. Zeng, J. Zhang, S. Ma, J. Li, S. Li and G. Xing, J. Nanobiotechnol., 2018, 16, 54.

69 J. K. Tee, L. X. Yip, E. S. Tan, S. Santitewagun, A. Prasath, P. C. Ke, H. K. Ho and D. T. Leong, Chem. Soc. Rev., 2019, 48, 5381.

70 F. Peng, M. I. Setyawati, J. K. Tee, X. Ding, J. Wang, M. E. Nga, H. K. Ho and D. T. Leong, Nat. Nanotechnol., 2019, 14, 279286.

71 J. Wang, L. Zhang, F. Peng, X. Shi and D. T. Leong, Chem. Mater., 2018, 30, 3759-3767. 